\title{
Performance of gas turbine-based plants during frequency drops
}

$\operatorname{AUTHOR}(\mathrm{S})$ :

Kakimoto, N; Baba, K

CITATION:

Kakimoto, N ...[et al]. Performance of gas turbine-based plants during frequency drops. IEEE TRANSACTIONS ON POWER SYSTEMS 2003, 18(3): $1110-1115$

ISSUE DATE:

2003-08

URL:

http://hdl.handle.net/2433/50073

\section{RIGHT:}

(c)2003 IEEE. Personal use of this material is permitted. However, permission to reprint/republish this material for advertising or promotional purposes or for creating new collective works for resale or redistribution to servers or lists, or to reuse any copyrighted component of this work in other works must be obtained from the IEEE. 


\title{
Performance of Gas Turbine-Based Plants During Frequency Drops
}

\author{
Naoto Kakimoto, Member, IEEE, and Kazuhiro Baba
}

\begin{abstract}
A combined cycle power plant, which combines a gas turbine and a steam turbine, can achieve high energy efficiency. Many combined cycle plants have been installed in the world. However, a large-scale blackout occurred in Malaysia in 1996. Combined cycle and gas turbine plants sequentially tripped out. The cause of this chain trip was thought to be a system frequency drop. Considering these backgrounds, it is important to study dynamic behavior of combined cycle plants. Several dynamic models of the combined cycle plant have been proposed. In our analysis, we use some of them and build a model for a single-shaft combined cycle plant. We execute numerical simulations to see how the combined cycle behaves when the system frequency drops.
\end{abstract}

Index Terms-Combined cycle, dynamic models, gas turbine, plant trip-out, under frequency.

\section{INTRODUCTION}

A combined cycle power plant, which combines a gas turbine and a steam turbine, can achieve high energy efficiency. The plant mainly consists of a gas turbine, a waste heat recovery boiler, and a steam turbine. This type of plant has high energy efficiency which exceeds $50 \%$. Many combined cycle plants have been installed in Japan. Their capacity is about $20000 \mathrm{MW}$ and $10 \%$ of the total generation.

However, a large-scale blackout occurred in Malaysia in 1996 [1]. Following a frequency drop of about $1.5 \mathrm{~Hz}$, combined cycle and gas turbine plants sequentially tripped out. The total generation loss was $5760 \mathrm{MW}$. Because of its importance, several studies were made on responses of combined cycle power plants to frequency drops [2]-[4]. Some models were developed based on models in [5] and [6] to represent practical plants, and then used to calculate responses to frequency changes. However, detailed analysis has not been made yet regarding how plant variables behave for frequency drops.

In this paper, we analyze dynamic behavior of a combined cycle plant for frequency drops. Several dynamic models of the combined cycle plant have been proposed [2]-[6]. We combine some of them and build a model for a single-shaft combined cycle plant. We execute numerical simulations to see how the combined cycle plant behaves when the system frequency drops.

\section{COMBINED CYCLE PLANT}

Fig. 1 shows a single-shaft combined cycle plant. The plant consists of a compressor, combustor, gas turbine, waste heat recovery boiler, steam turbine, and a generator. The compressor compresses air, and sends it to the combustor. The combustor

Manuscript received January 20, 2003.

The authors are with Kyoto University, Kyoto 606-8501, Japan. Digital Object Identifier 10.1109/TPWRS.2003.814884

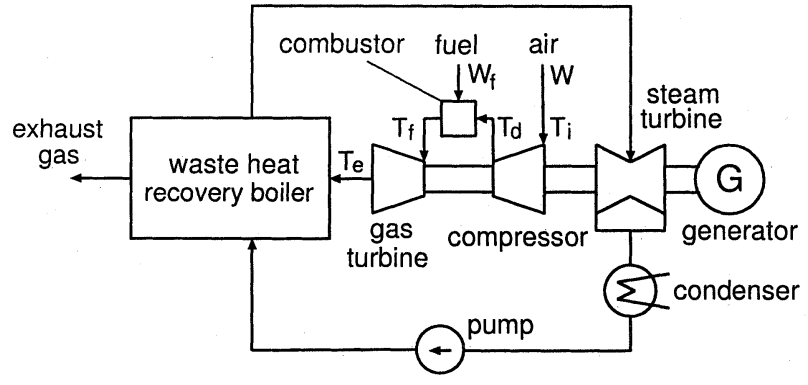

Fig. 1. Single-shaft combined cycle plant.

burns this air with fuel, and makes high temperature and high pressure combustor gas. This combustor gas drives the gas turbine. The waste heat recovery boiler collects some energy of exhaust gas, and drives the steam turbine. Plant power output is the sum of the gas turbine and the steam turbine power outputs. The gas turbine produces about two thirds of the total power output, and the steam turbine produces the rest.

Since the air is adiabatically compressed, compressor discharge temperature $T_{d}(\mathrm{~K})$ is given as follows [6]:

$$
\begin{aligned}
T_{d} & =T_{i}\left(1+\frac{x-1}{\eta_{c}}\right) \\
x & =\left(P_{r_{o}} W\right)^{\gamma-1 / \gamma}
\end{aligned}
$$

where $T_{i}(\mathrm{~K})$ is compressor inlet temperature and equals ambient temperature, $\eta_{c}$ is compressor efficiency, $x$ is compressor temperature ratio, $P_{r o}$ is design compressor pressure ratio, $W$ is airflow in per unit of its rated value, and $\gamma$ is ratio of specific heats. The airflow $W$ depends on the ambient temperature $T_{i}$ and the atmospheric pressure $P_{a}$

$$
W=W_{a} \frac{P_{a}}{P_{a o}} \frac{T_{i o}}{T_{i}}
$$

where subscript " $o$ " denotes rated value, and $W_{a}$ is the airflow at $P_{a o}$ and $T_{i o}$. We assume $P_{a}=P_{a o}$.

Gas turbine inlet temperature $T_{f}(\mathrm{~K})$ is given by

$$
T_{f}=T_{d}+\left(T_{f o}-T_{d o}\right) \frac{W_{f}}{W}
$$

where $W_{f}$ is fuel flow in per unit of its rated value. The fuel flow is a negligible amount compared with the airflow.

Gas turbine exhaust temperature $T_{e}(\mathrm{~K})$ is described as follows:

$$
T_{e}=T_{f}\left[1-\left(1-\frac{1}{x}\right) \eta_{t}\right]
$$

where $\eta_{t}$ is turbine efficiency. The exhaust gas flow is practically equal to the airflow. 


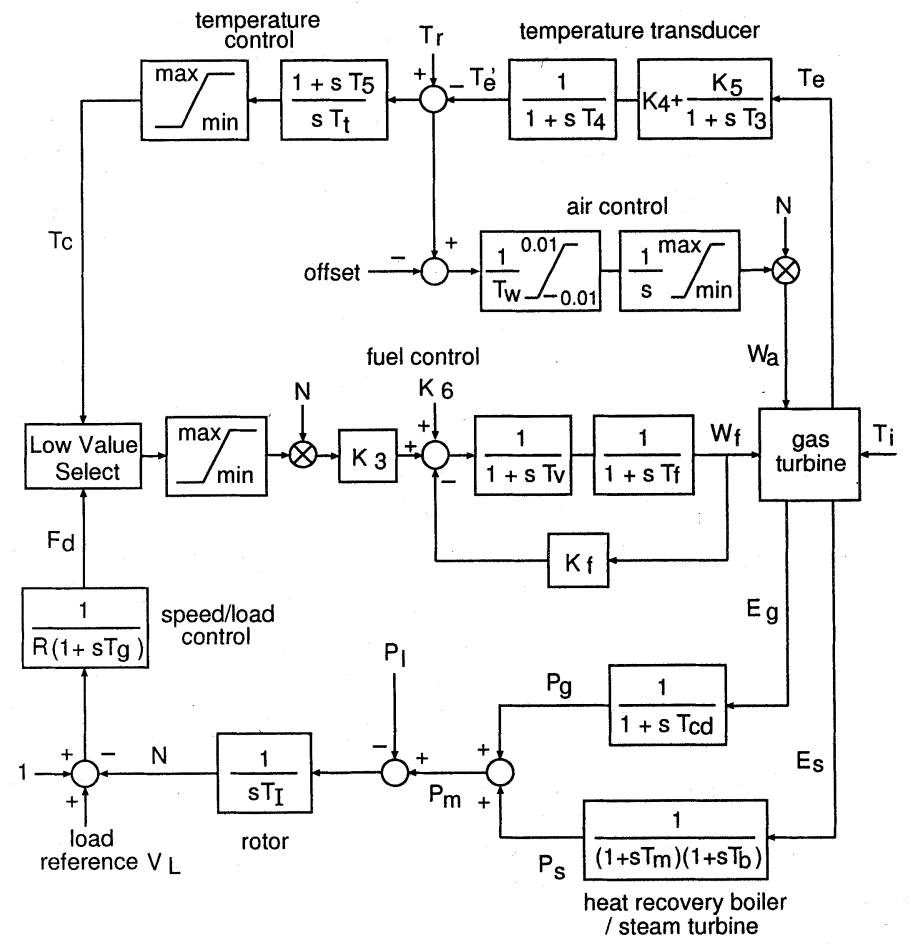

Fig. 2. Model of combined cycle.

\section{MODEL}

Fig. 2 shows a model of the combined cycle plant. It consists of several blocks. There are four blocks related with speed/load control, temperature control, fuel control, and air control. Remaining blocks describe gas turbine, waste heat recovery boiler/steam turbine, rotor shaft, and temperature transducer. The input and output variables of each block are linked as shown in the figure. This model is based on models of [5] and [6], whose validity has been tested in [2]-[4] and [7]. We briefly review each block.

The speed/load control block determines the fuel demand $F_{d}$ according to the load reference $V_{L}$ and the rotor speed deviation $(1-N)$. Descriptions of parameters are provided in the Appendix in Table 1 and Table 2.

The temperature control block restricts the exhaust temperature $T_{e}\left({ }^{\circ} \mathrm{C}\right)$ not to injure the gas turbine. The measured exhaust temperature $T_{e}^{\prime}$ is compared with the reference temperature $T_{r}\left({ }^{\circ} \mathrm{C}\right)$. The output is the temperature control signal $T_{c}$.

The fuel demand $F_{d}$ is compared with the temperature control signal $T_{c}$ in the fuel control block. The lower value is selected by the low value selector, and it determines the fuel flow $W_{f}$.

The air control block adjusts the airflow $W$ so as to attain the desired exhaust temperature [8]. The exhaust temperature $T_{e}\left({ }^{\circ} \mathrm{C}\right)$ is kept lower than $T_{r}\left({ }^{\circ} \mathrm{C}\right)$, by an appropriate offset, for example, $1 \%$ of its rated value. $T_{e}^{\prime}$ is used for $T_{e}$, again. The airflow is adjusted by compressor inlet guide vanes (IGV). Based on explanations in [8] and [2], we use the model in Fig. 2. The adjustable airflow is about $30 \%$ of the rated airflow. The adjusting speed is slow compared with the fuel flow. We assume the airflow changes at 1\%/s at most from the test in [3]. The airflow $W_{a}$ is proportional to the rotor speed $N[6]$.

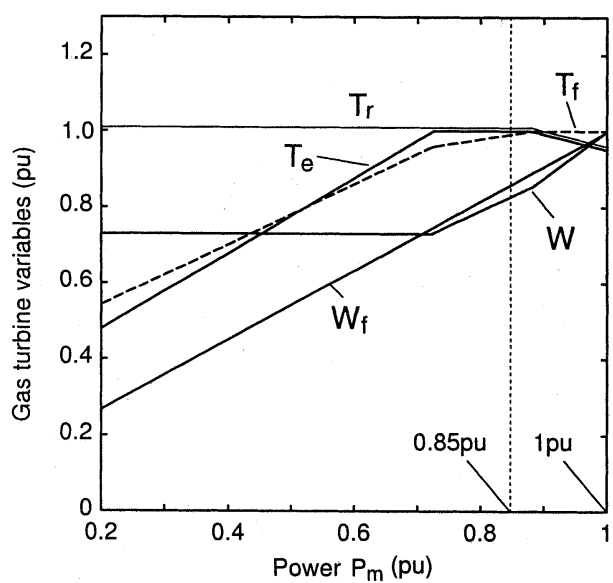

Fig. 3. Heatbalance.

Once the fuel flow $W_{f}$, the airflow $W_{a}$, and the inlet temperature $T_{i}$ are given, the temperatures $T_{d}, T_{f}, T_{e}$, and the airflow $W$ are determined by (1)-(5). With these values, the net energy supplied to the gas turbine is given by

$$
E_{g}=K_{0}\left\{\left(T_{f}-T_{e}\right)-\left(T_{d}-T_{i}\right)\right\} W
$$

where $K_{0}$ is a constant. This energy is converted to the power $P_{g}$ after a transport delay $T_{c d}$.

The energy collected by the heat recovery boiler and the steam turbine is

$$
E_{s}=K_{1} T_{e} W
$$

where $K_{1}$ is a constant. This energy changes to the power $P_{s}$ after time delays denoted by $T_{m}$ and $T_{b}$.

By summing $P_{g}$ and $P_{s}$, we obtain the plant power output $P_{m}$. The rotor speed $N$ varies if there is any difference between the power output $P_{m}$ and the load power $P_{l}$. In this paper, $P_{l}$ is assumed to be proportional to $N^{\alpha}$, where $\alpha$ is a constant. $T_{I}$ is the time constant of the rotor.

\section{CASE Study}

There are many power plants in practical power systems. In this study, we consider a small system composed of a combined cycle plant and a load. Their models have been described in the preceding section. We regard this system as a part of a large system.

\section{A. System Parameters}

As an example, we consider a $1100^{\circ} \mathrm{C}$ class single-shaft combined cycle plant. Its rated power output is $160 \mathrm{MW}$ (gas turbine 106.7 MW, steam turbine 53.3 MW). On the gas turbine, we use typical parameters provided in [5], while they change for practical turbines [7]. As for the steam turbine, we use parameters in [6]. The parameters are listed in the Appendix.

Fig. 3 specifies how to control the exhaust temperature. The fuel flow $W_{f}$ linearly increases with the power output $P_{m}$. The exhaust temperature $T_{e}$ rises and reaches its rated value. The airflow control in Fig. 2 begins to increase the airflow $W$ in order to keep $T_{e}$ constant. If $T_{e}$ exceeds the reference temperature $T_{r}$, 


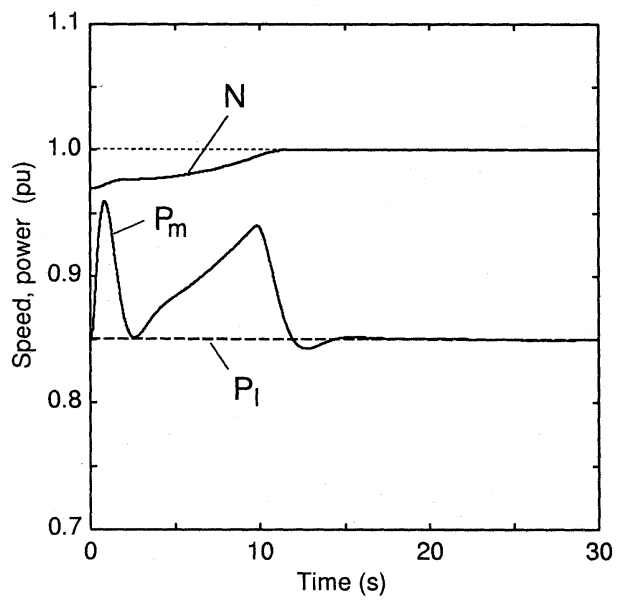

(a)

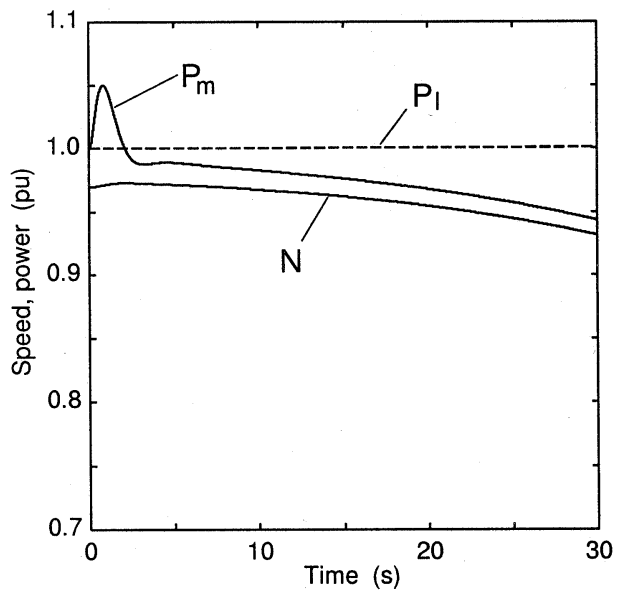

(b)

Fig. 4. Response to frequency drop (0.97 p.u.). (a) $P_{m i}=0.85$ p.u. (b) $P_{m i}=$ 1 p.u.

the temperature control acts. Its dynamics is shown in Fig. 2, too. $T_{r}$ is higher than $T_{e}$ by $1 \%$. The turbine inlet temperature $T_{f}$ still increases. If $T_{f}$ reaches its rated value, $W$ increases more rapidly for $T_{f}$ not to rise any more. $T_{e}$ decreases as a result to $95 \%$ at the rated power. The exhaust temperature is thus kept high at part load conditions. This airflow control facilitates collection of exhaust gas energy in the waste heat recovery boiler [8].

\section{B. Response to Frequency Drop}

First, we consider cases in which this system is separated from the large system with a balanced load following a frequency drop. Fig. 4 shows two cases where the frequency instantly drops to 0.97 p.u., and the initial power output $P_{m i}$ is 0.85 or 1 p.u. $P_{l}$ is assumed to be constant (i.e., $\alpha=0$ ), and accordingly $P_{l}=P_{m i}$.

Fig. 4(a) shows the case where the initial power output $P_{m i}$ is 0.85 p.u. The rotor speed $N$ drops to 0.97 p.u, but returns to the normal value in $12 \mathrm{~s}$. The system is stable in this case. The power output $P_{m}$ quickly increases, and quickly decreases. Since its value is nearly equal to $P_{l}$, the rotor is not accelerated for a few moments. However, $P_{m}$ slowly increases, and exceeds $P_{l}$. The rotor consequently recovers speed.

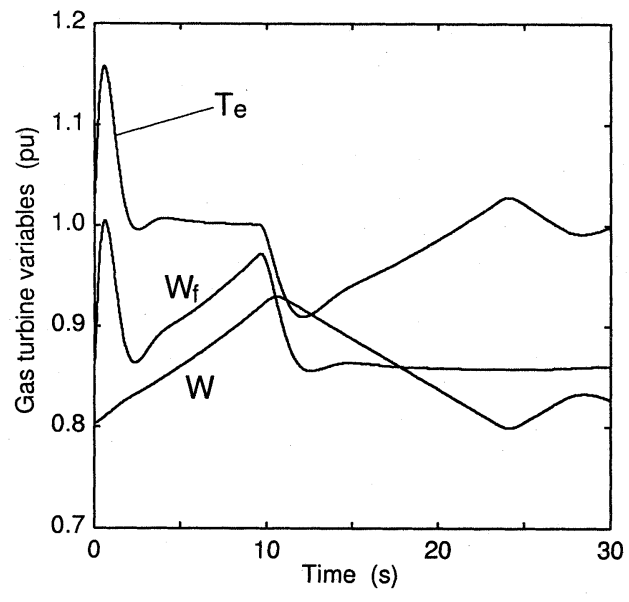

(a)

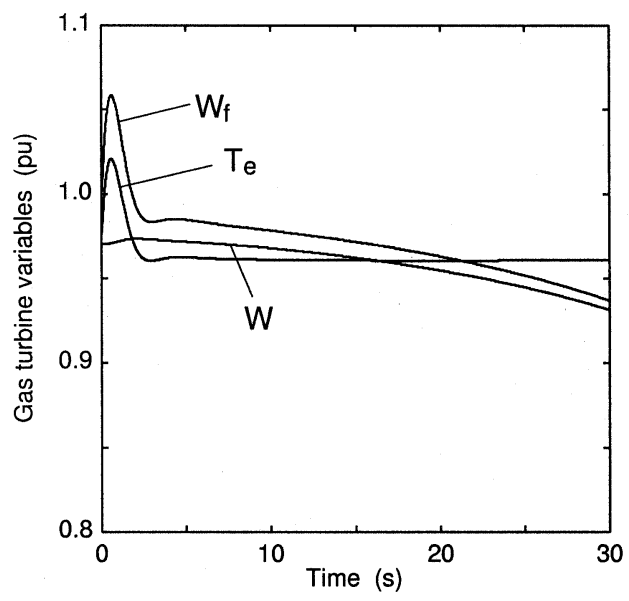

(b)

Fig. 5. Response to frequency drop ( 0.97 p.u.). (a) $P_{m i}=0.85$ p.u. (b) $P_{m i}=$ 1 p.u.

Fig. 4(b) shows the case where $P_{m i}$ is 1 p.u. In this case, the rotor speed $N$ continues to fall, and does not return to the normal value. This is an unstable case. The initial increase and decrease in $P_{m}$ is similar to the stable case. However, after that, $P_{m}$ slowly decreases. Its value is lower than $P_{l}$, and accordingly the rotor loses speed with time.

\section{Analysis of Plant Outputs}

As observed in Fig. 4, the rotor speed is governed by $P_{m}$, so it is important to understand its behavior.

Fig. 5 shows three variables $W_{f}, T_{e}$, and $W$. The time variation of the fuel flow $W_{f}$ is similar to that of $P_{m}$ in Fig. 4. Since the rotor speed $N$ drops, the speed control increases $W_{f}$. However, the exhaust temperature $T_{e}$ rises simultaneously, and it exceeds the reference temperature $T_{r}$. The temperature control then acts to restrict the fuel flow. These controls explain the initial behavior of $P_{m}$.

The exhaust temperature $T_{e}$ lowers below the reference temperature $T_{r}=1.01 \mathrm{pu}$ in Fig. 5(a). However, $T_{e}$ remains above $T_{r}=0.96 \mathrm{pu}$ in Fig. 5(b). This difference is caused by the airflow control. The airflow is adjusted by the IGVs in reference to the exhaust temperature $T_{e}$. When the initial power output $P_{m i}$ is 0.85 p.u., the airflow $W$ increases slowly. As a result, 


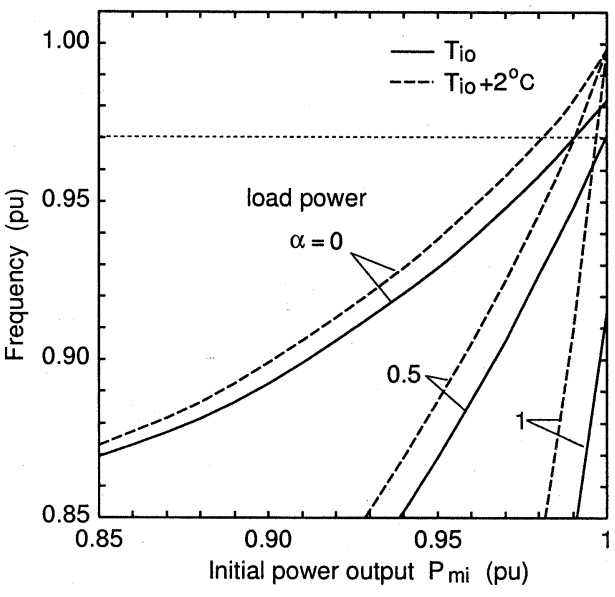

(a)

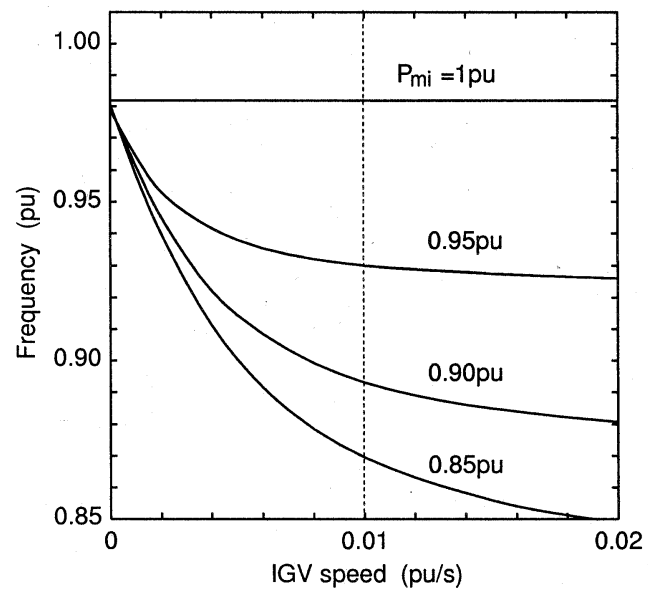

(b)

Fig. 6. Critical frequency.

the exhaust temperature lowers, which subsequently allows the fuel flow $W_{f}$ to increase. The slow increase in $P_{m}$ is thus explained. However, when $P_{m i}$ is 1 p.u., the IGVs are fully open and the airflow does not increase any more. Hence, any increase in the fuel flow is suppressed by the temperature control.

\section{Critical Frequency}

The system is stable for the frequency drop to $0.97 \mathrm{p} . \mathrm{u}$. when $P_{m i}$ is 0.85 p.u. However, if the frequency drops below a critical value, the system becomes unstable. Fig. 6 shows some variations of the critical frequency.

In Fig. 6(a), the initial power output $P_{m i}$ is changed, where the load power $P_{l}$ is proportional to $N^{\alpha}$. The solid lines show cases in which the ambient temperature $T_{i}$ is $T_{i o}$. First, we observe the case of $\alpha=0$ (i.e., constant power). The critical frequency rises as $P_{m i}$ increases. For example, the system is stable for a $13 \%$ frequency drop at $P_{m i}=0.85$ p.u., but it becomes unstable for a $2 \%$ frequency drop at $P_{m i}=1$ p.u.. The system at $P_{m i}=1 \mathrm{pu}$ is therefore weak for frequency drops. Next, we change $\alpha$ from 0 to 3 . Since the load power $P_{l}$ decreases in proportion to $N^{\alpha}$, the system becomes more stable as $\alpha$ increases. If $\alpha>1.26$, the system is stable for $15 \%$ or more frequency drops. The broken lines in the figure show cases where the ambient temperature is higher than $T_{i o}$ by $2^{\circ} \mathrm{C}$. In these cases, the

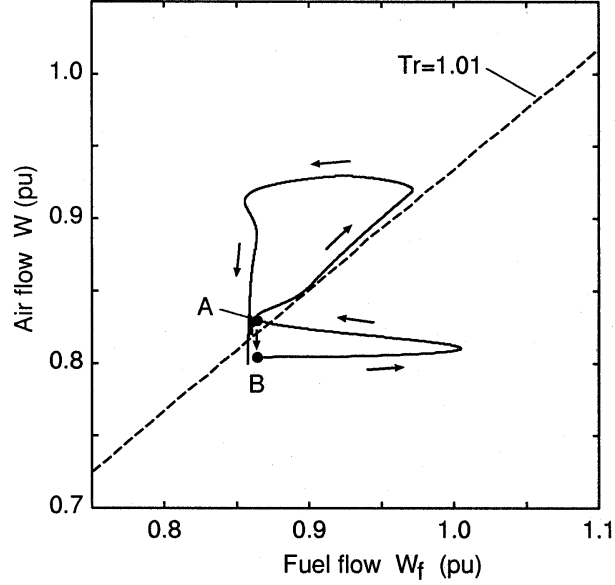

(a)

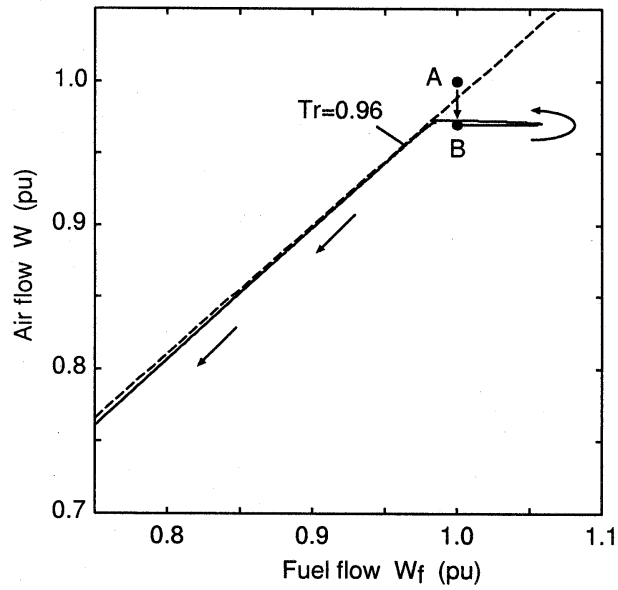

(b)

Fig. 7. Fuel flow and air flow. (a) $P_{m i}=0.85$ p.u. (b) $P_{m i}=1$ p.u.

critical frequency moves upward. This is conspicuous when $P_{m i}$ is 1 p.u. The system becomes unstable for a frequency drop to 0.997 p.u. These results are related with the frequency characteristics of the power output $P_{m}$. We examine it in Section VI.

In Fig. 5(a), the airflow varies slowly. If it varies faster, the fuel flow can increase more rapidly while keeping the exhaust temperature under $T_{r}$. Its speed may affect the stability of the system. Fig. 6(b) shows some variation of the critical frequency with the IGV speed, where $\alpha=0$. For $P_{m i}=0.85 \sim 0.95 \mathrm{pu}$, the critical frequency lowers as the IGV speed increases. Conversely, it rises as the IGV speed reduces. This is what we expected. However, if $P_{m i}=1$ p.u., the IGV speed does not influence the critical frequency at all. The reason is that the IGVs are fully open, and that the airflow does not increase.

\section{EFFECT OF TEMPERATURE CONTROL}

The temperature control is a crucial factor in the above phenomenon. The exhaust temperature is determined by the fuel flow and the airflow, and it determines whether the temperature control operates or not. In this section, we examine the phenomenon in terms of the fuel flow and the airflow.

Fig. 7 shows how the fuel and air flows move on the $W_{f}-W$ plane, where their values are taken from Fig. 4. For simplicity, 


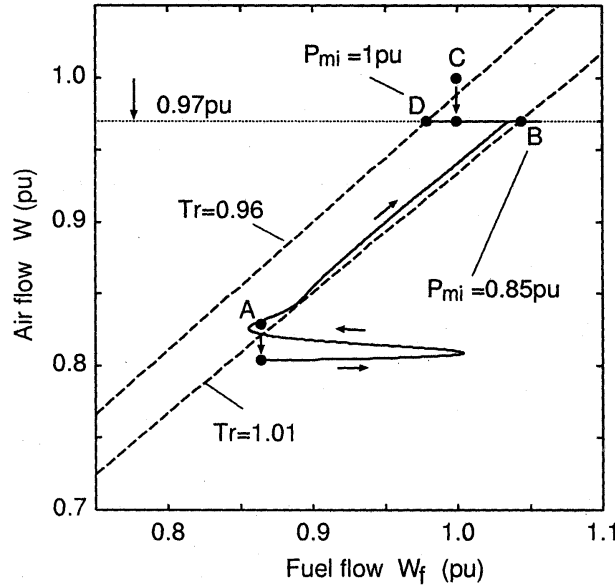

(a)

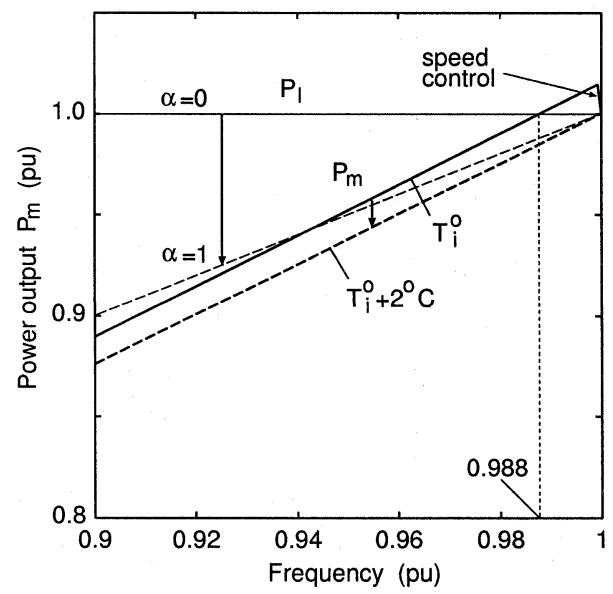

(b)

Fig. 8. Response to constant frequency drop.

we call a point $\left(W_{f}, W\right)$ "state." In Fig. 7(a), the state moves from A to A via B. The broken line shows combinations of $W_{f}$ and $W$ corresponding to the exhaust temperature 1.01 p.u. or 0.96 p.u. Under the line, the exhaust temperature is higher than the reference temperature $T_{r}$, and the temperature control acts.

Fig. 7(a) shows the case where the initial power output $P_{m i}$ is 0.85 p.u. The state jumps from A to B immediately after the frequency drop, and then it moves right due to the speed control. Since the state is under the broken line, the temperature control moves the state left. As the airflow slowly increases, the state moves upward along the broken line. Once the rotor recovers speed, the state moves left and then downward. The state finally returns to A.

Fig. 7(b) shows the case where $P_{m i}$ is 1 p.u. The broken line corresponds to the exhaust temperature 0.96 p.u. The state jumps from A to B, moves right, and then left. This is similar to Fig. 7(a). However, the inlet guide vanes are full-open, and the airflow does not increase. Furthermore, the airflow slowly decreases because it is proportional to the rotor speed. The fuel flow is restricted by the temperature control. As the rotor loses speed, the state moves downward along the broken line.

It is thus observed that the state moves along the broken line under the temperature control.
TABLE I

GAS TURBINE PARAMETERS

\begin{tabular}{c|l|r}
\hline \multicolumn{2}{c|}{ parameter } & value \\
\hline$T_{i o}$ & compressor inlet temperature & $30\left({ }^{\circ} \mathrm{C}\right)$ \\
$T_{d o}$ & compressor discharge temperature & $390\left({ }^{\circ} \mathrm{C}\right)$ \\
$T_{f o}$ & gas turbine inlet temperature & $1085\left({ }^{\circ} \mathrm{C}\right)$ \\
$T_{e o}$ & gas turbine exhaust temperature & $532\left({ }^{\circ} \mathrm{C}\right)$ \\
\hline$P_{r o}$ & compressor pressure ratio & 11.5 \\
$\gamma$ & ratio of specific heat & 1.40 \\
$\eta_{c}$ & compressor efficiency & 0.85 \\
$\eta_{t}$ & turbine efficiency & 0.85 \\
\hline$K_{0}$ & gas turbine output coefficient & 0.003030 \\
$K_{1}$ & steam turbine output coefficient & 0.000428 \\
\hline
\end{tabular}

TABLE II

COMBINED CYCLE PARAMETERS

\begin{tabular}{c|l|r}
\hline \multicolumn{1}{|c|}{ parameter } & value \\
\hline$R$ & speed regulation & 25 \\
$T_{g}$ & governor time constant & 0.05 \\
$K_{4}$ & gain of radiation shield & 0.8 \\
$K_{5}$ & gain of radiation shield & 0.2 \\
$T_{3}$ & radiation shield time constant & 15 \\
$T_{4}$ & thermocouple time constant & 2.5 \\
$T_{5}$ & temperature control time constant & 3.3 \\
$T_{t}$ & temperature control integration rate & 250 \\
$T_{c m a x}$ & temperature control upper limit & $1: 1$ \\
$T_{c m i n}$ & temperature control lower limit & 0 \\
\hline$F_{d m a x}$ & fuel control upper limit & 1.5 \\
$F_{d m i n}$ & fuel control lower limit & -0.1 \\
$K_{3}$ & ratio of fuel adjustment & 0.77 \\
$K_{6}$ & fuel valve lower limit & 0.23 \\
$T_{v}$ & valve positioner time constant & 0.05 \\
$K_{f}$ & fuel system feedback constant & 0 \\
$T_{f}$ & fuel system time constant & 0.4 \\
\hline$W_{\max }$ & air control upper limit & 1.0 \\
$W_{\min }$ & air control lower limit & 0.73 \\
$T_{w}$ & air control time constant & 250 \\
\hline$T_{c d}$ & compressor volume time constant & 0.2 \\
$T_{m}$ & tube metal heat capacitance time & 5 \\
& constant of waste heat recovery boiler & \\
$T_{b}$ & boiler storage time constant of waste & 20 \\
& heat recovery boiler & 18.5 \\
$T_{I}$ & turbine rotor time constant & \\
\hline
\end{tabular}

\section{FIXED FREQUENCY}

Fig. 7 corresponds to cases where a combined cycle plant is separated from a large system, and its rotor speed varies with time. In this section, we consider a plant in a large system whose frequency is not affected by the plant.

Fig. 8(a) shows some variation of the fuel and air flow. The frequency instantly drops to 0.97 p.u. again, and the rotor speed $N$ is fixed at this value. If $P_{m i}$ is 0.85 p.u., the state moves from A to $B$. The airflow increases till the inlet guide vanes fully open, and the fuel flow increases until the exhaust temperature reaches 1.01 p.u. If $P_{m i}$ is 1 p.u., the state moves from C to D. The inlet guide vanes are full-open, and the fuel flow is restricted by the temperature control. If $T_{r}$ is adjusted to 0.96 p.u. to protect the gas turbine, the point $\mathrm{B}$ moves to $\mathrm{D}$.

Fig. 8(b) shows the power output $P_{m}$ at the point D. $P_{m}$ varies with the frequency. $P_{m}$ is smaller than $P_{l}$ (1 p.u.) for frequencies below 0.988 p.u. For example, $P_{m}$ decreases to 0.977 p.u. at the frequency 0.97 p.u., so the system needs $2.3 \%$ power reserve for $3 \%$ frequency drop. If the ambient temperature $T_{i}$ is higher than $T_{i o}$ by $2^{\circ} \mathrm{C}, P_{m}$ moves downward. This is because the exhaust temperature $T_{e}$ rises according to (1)-(5), and the temperature 
control overrides the speed/load control. Almost the same result is obtained when the offset in the air control is zero, and accordingly $T_{r}$ is 0.95 p.u. The power output $P_{m}$ is nearly proportional to $N^{1.26}$. This explains the results in Fig. 6(a). When $P_{l}$ is constant $(\alpha=0)$ or proportional to $N(\alpha=1), P_{m}$ decreases faster than $P_{l}$, so appropriate power reserve must be prepared. It has been shown by tests that many loads have $\alpha \leq 1$ [9], [10]. The characteristics of $P_{m}$ is therefore important, and some investigation has been made in [4].

\section{CONCLUSIONS}

In this paper, we examined how a single-shaft combined cycle plant behaves for frequency drops. The obtained results are summarized as follows:

1) Following a frequency drop, the temperature control soon overrides the speed control, and restricts the fuel flow about its initial value.

2) The fuel flow then slowly increases as the inlet guide vanes open. Their speed considerably affects the stability of the plant.

3) If the inlet guide vanes open fully, the temperature control and the frequency determine the fuel flow and accordingly the power output.

4) The power output is approximately proportional to $N^{1.26}$ in our model. This frequency characteristics must be considered in estimating power reserve.

Lastly, although this paper addresses a combined cycle plant, the above results are applicable to any gas turbine-based plant which operates at or near exhaust gas temperature limits.

\section{APPENDIX}

See Table 1 and Table 2 on previous page.

\section{ACKNOWLEDGMENT}

The authors would like to acknowledge the suggestions of Prof. T. Takuma in our study.

\section{REFERENCES}

[1] "Large-scale blackout in Malaysia," in Kaigai Denryoku (Foreign Power): Japan Electric Power Information Center, Inc., 1996, pp. 103-104.

[2] T. Inoue, Y. Sudo, A. Takeuchi, Y. Mitani, and Y. Nakachi, "Development of a combined cycle plant model for power system dynamic simulation studies," Trans. Inst. Elect. Eng. Jpn., vol. 119-B, no. 7, pp. 788-797, 1999.

[3] S. Suzaki, K. Kawata, M. Sekoguchi, and M. Goto, "Combined cycle plant model for power system dynamic simulation study," Trans. Inst. Elect. Eng. Jpn., vol. 120-B, no. 8/9, pp. 1146-1152, 2000.

[4] K. Kunitomi, A. Kurita, H. Okamoto, Y. Tada, S. Ihara, P. Pourbeik, W. W. Price, A. B. Leirbukt, and J. J. Sanchez-Gasca, "Modeling frequency dependency of gas turbine output," Proc. IEEE/Power Eng. Soc. Winter Meeting, Jan. 2001.

[5] W. I. Rowen, "Simplified mathematical representations of heavy-duty gas turbines," Trans. Amer. Soc. Mech. Eng., vol. 105, pp. 865-869, Oct. 1983.

[6] F. P. de Mello and D. J. Ahner, "Dynamic models for combined cycle plants in power system studies," IEEE Trans. Power Syst., vol. 9, pp. 1698-1708, Aug. 1994.

[7] L. N. Hannett and A. Khan, "Combustion turbine dynamic model validation from tests," IEEE Trans. Power Syst., vol. 8, pp. 152-158, Feb. 1992.

[8] W. I. Rowen and R. L. Van Housen, "Gas turbine airflow control for optimum heat recovery," Trans. Amer. Soc. Mech. Eng. J. Eng. Power, vol. 105, pp. 72-79, Jan. 1983.

[9] C. Concordia and S. Ihara, "Load representation in power system stability studies," IEEE Trans. Power Apparat. Syst., vol. PAS-101, pp 969-977, Apr. 1982.

[10] T. Frantz, T. Gentile, S. Ihara, N. Simons, and W. Waldron, "Load behavior observed in LILCO and RG\&E systems," IEEE Trans. Power Apparat. Syst., vol. PAS-103, no. 4, pp. 819-831, Apr. 1984.

Naoto Kakimoto (M'78) was born in 1952 in Japan. He received the Ph.D degree in electrical engineering from Kyoto University, Kyoto, Japan, in 1982. Currently, he is an Associate Professor at Kyoto University. His current interests are power system stabilities, power electronics devices, and distributed power generation.

Dr. Kakimoto is a member of IEE of Japan.

Kazuhiro Baba was born in 1978 in Japan. He received the M.S. degree in electrical engineering from Kyoto University, Kyoto, Japan, in 2002.

His current interest is stability of combined cycle power plant. Mr. Baba is a member of IEE of Japan. 